Send your letters to the editor, British Dental

Journal, 64 Wimpole Street, London W1G 8YS

E-mail bdj@bda.org

Priority will be given to letters less than 500

words long. Authors must sign the letter,

which may be edited for reasons of space

\section{Developing skills and art}

Sir, Dr Gibson makes an excellent point about the importance of art in dentistry $(B D J$ 2005; 199: 247). Regarding evidence-based dentistry (EBD) however, there is a misunderstanding. By definition (and by practice), EBD does not dictate what to do. Instead, it offers decision support by providing the best evidence available to integrate both with patient preferences and with a professional's highly developed skills and art. Developing skills and art are not bypassed but instead, are an essential aspect of delivering high quality patient care. ${ }^{1}$ There are parallels with periodontics. Many clinicians use plaque indices in patient care. However, few would blindly apply the values of the indices to assessing oral hygiene without considering other issues such as when the patient last brushed their teeth, their susceptibility to periodontal diseases, etc. Numbers alone do not make decisions.

What EBD does provide is the best available evidence for effectiveness and harms and tries to quantify the probability of achieving such outcomes where the data are available. Alternatively, it might own up to a lack of good evidence if this is the case. Such evidence is derived by stripping away accumulated bias and opinion, objectively assessing research quality and by including the totality of evidence, whether randomised, observational study or qualitative research. Each professional and each patient must make their own decisions on how to apply this information since it will be different for each particular circumstance. Decisions are therefore also more individual than generic. Now if $\mathrm{Dr}$ Gibson would prefer not to have such information available to aid decision making, that would be surprising. I. Needleman, D. Mole, J. Suvan London

1. Needleman I, Worthington H, Moles D. Evidence-based periodontology, systematic reviews and research quality. Periodontology 2000 2005; 37: 12-28.

doi: 10.1038/sj.bdj.4813074

\section{Dentistry and myeloma}

Sir, having been diagnosed with multiple myeloma in 2004, I read the recent paper by Ariyaratnam et al. (BDJ 2005; 199 :

433-435) with particular attention.

While the case report is interesting, few dentists will see such an atypical presentation. On the other hand, they will come across patients with multiple myeloma and I was disappointed by the discussion of this condition. Too much of the information in this section has been gleaned from outdated sources. Specifically, I would draw the authors' attention to the following points.

The limitation of the staging system of Durie-Salmon has been recognised and it has been replaced by the new International Staging System (ISS). ${ }^{1}$ Following a collaborative effort by investigators from 17 institutions worldwide, patients can be divided into three distinct stages and prognostic groups solely on the basis of serum 2-microglobulin and albumin levels.

The use of melphalan is nowadays usually limited to older patients who are not candidates for stem cell transplant since it can prevent adequate stem cell mobilisation. Even the role of autologous stem cell transplants is being questioned, as they seem to offer the greatest benefit to those with disease refractory to induction therapy. Amongst the newer treatments, Thalidomide has been used extensively for the past five years but may produce severe side effects, including permanent peripheral neuropathy, when used in high doses. Greater success without neurotoxicity has been reported for Revlimid (lenalidomide), an analogue of Thalidomide. Another widely used new treatment is Velcade (bortezomid). All of these drugs may be more effective when used in combinations with each other and with steroids such as dexamethasone or prednisolone. Promising current research includes monoclonal antibodies and Heat Shock Protein (Hsp90) inhibitor.

However, the most serious omission was any reference to the problem of jaw osteonecrosis following prolonged use of bisphosphonates such as Aredia (pamidronate) and Zometa (zoledronic acid). This has been widely reported since 2003 and indeed mentioned in two recent editions of this journal. ${ }^{2}$ These drugs are routinely administered by monthly infusion to myeloma patients to prevent bone damage but may trigger problems with bone healing in a small subset of patients following dental surgery. This includes tooth extraction, endodontics and periodontal treatment. Close cooperation is required with the patient's haematologist in these circumstances and it may be advisable to stop the bisphosphonates for three months before any treatment.

Therefore, my advice to any dentist faced with a patient with myeloma would be:

- Check on the International Myeloma Foundation website at www.myeloma.org.uk to update yourself on the condition.

- Fully investigate and note the patient's past and present treatment and medication.

- Contact the patient's haematologist, particularly if any surgery is required.

The aim of contemporary treatment should be to characterise the myeloma, ideally at a molecular level, and tailor the treatment to the individual patient. I noted the authors' gloomy statement, 'myeloma ultimately leads to death'. Well, yes - but life itself is a fatal complaint and does not consist of holding good cards but in playing those you hold well! D. Regan Matlock

1. Greipp P R, San Miquel J, Durie BG, et al. Internationa staging system for multiple myeloma. J Clin Oncol 2005; 23: 3412-3420

2. Marx R E Pamidronate (Aredia) and zoledronate (Zometa) induced avascular necrosis of the jaws: a growing epidemic. J Oral Maxillofac Surg 2003; 61 1115-1117.

doi: $10.1038 /$ sj.bdj.4813075

Need for orthodontic truth

Sir, in the past GDPs were respected as long-term monitors of orthodontic success and this enabled them to contribute substantially to the debate. There are now moves afoot to create an orthodontic certificate or diploma for general dentists who have such interests. What are their thoughts about the current range of 
treatment options available and how are they able to use them?

As some had forecast, "orthodontic registration' has led to a restriction in the range of orthodontic techniques practised. Dental students are currently advised to limit orthodontic treatment to simple cases, while those general dentists who until 1999 provided over half the orthodontic treatment in the UK using a range of fixed and functional techniques, have by now, either been grandfathered in as specialists or are progressively retiring. They are being replaced by 'Registered Orthodontists' who have been taught a relatively unified form of fixed appliance therapy.

In 1965 the British Association of Orthodontics (BAO) was established to help redress similar imbalances and to represent those clinicians who felt that the teaching at some hospitals was too prescriptive. At that time growth guidance methods such as 'Functional Appliances', 'Non-Extraction', and 'Early Treatment' were viewed with suspicion and it was BAO that helped to make them acceptable, subsequently developing into a powerful organisation. However in 1994 BAO combined with BSSO to form the British Orthodontic Society (BOS). Following this the influence of the schools became re-established and fixed appliances, frequently coupled with extractions, again predominate.

Fixed appliances undoubtedly provide an effective and predictable means of straightening teeth but have been criticised for a number of possible side effects, and also because the teeth have a tendency to relapse in the long term. Is it healthy for one type of treatment to predominate to such an extent when in many countries and at different times other methods have been preferred?

Functional appliances represent only 3\% of NHS treatment. Is this because they are ineffective, unreliable or because fees have been reduced to discourage their use?

Undoubtedly their success is dependent on co-operation, but this decision is often made by the authorities or by orthodontists who prefer fixed therapy. Many parents are left unable to pursue non-extraction options that are available abroad. This is despite the fact that there is really no firm evidence either way.

Recently, at the behest of some orthodontists there has been a concerted attempt to restrict (suppress) 'growth guidance' and several general practitioners who use functional appliances have found themselves targeted by the GDC for 'overstating their effectiveness'. Is this reasonable when the truth is so clouded by entrenched beliefs coupled with so few facts?

We think the truth can only be established by a truly independent enquiry and we have offered to pay for the substantial cost of such an enquiry, but the BOS has so far been reluctant to participate. We would ask BDA members to support this offer of a scientific enquiry so that an appropriate balance can be established based on truth.

Could any concerned dentists or orthodontists contact us either via the journal or direct to contact@ol2enwide.biz.

A. Hedger, Y. George , N. Stimson, T. Heesom Surrey

doi: 10.1038/sj.bdj.4813076

\section{Cause for concern}

Sir, the letter from Mr Parker and the response to it from Professor Avery et al. (BDJ 2005; 199: 405, 407) both refer to the vacancy survey carried out by the BDA's Central Committee for Hospital Dental Services (CCHDS). It is perhaps helpful to clarify the background to this.At a meeting of the full CCHDS, held in Sheffield on 12 November 2004, considerable concern was expressed from several quarters at the large number of unfilled consultant posts in the dental specialties across the UK - especially in the fields of orthodontics and oral and maxillofacial surgery (OMFS). The existence of a number of unfilled Specialist Registrar posts in OMFS was also noted at that stage, possibly attributable to the drop-out rate from the specialty following the introduction of the mandatory second primary degree.

It was, therefore, decided that a national survey would be carried out whereby all the elected regional representatives of CCHDS reported, by email, any posts that were currently unfilled or expected to become vacant over the coming year (large numbers of retirements are anticipated across the NHS in 2005-6, as consultants reach their optimum pension eligibility).

The first results were completed by the end of December 2004. At a meeting I had with the Chief Dental Officer for England on 10 January 2005, the CDO (Professor Raman Bedi) requested sight of the details of our survey results, and these were duly provided.

Subsequently, the survey has been intermittently repeated, with the most recent version (July 2005) still reporting significant levels of vacancies.

It is true, of course, that any such survey can only be a snapshot of the situation at any given moment and that change can take place rapidly. However, the level of unfilled vacancies apparent within the hospital dental specialties continues to be a cause for concern.
A. Flower
Chair, Central Committee for Hospital
Dental Services
By email
doi: 10.1038/sj.bdj.4813077 